\title{
PENERAPAN FUNGSI MANAJEMEN KEPALA RUANGAN DALAM PENGENDALIAN MUTU KEPERAWATAN
}

\author{
Nurdiana $^{1,4^{*}}$, Rr. Tutik Sri Hariyati ${ }^{2}$, Siti Anisah ${ }^{3}$ \\ ${ }^{1}$ Program Studi Magister Kepemimpinan dan Manajemen Keperawatan, \\ Kampus UI Depok 16424, Indonesia \\ ${ }^{2}$ Fakultas Ilmu Keperawatan Universitas Indonesia, Kampus UI Depok 16424, Indonesia \\ ${ }^{3}$ RSPAD Gatot Soebroto, Jl. Dr. Abdul Rahman Saleh, Jakarta, 10410, Indonesia \\ ${ }^{4}$ RSUPN Dr. Cipto Mangunkusumo, J1. Diponegoro 71, Jakarta, 10430, Indonesia \\ *)E-mail: nurdiana.ismangil@gmail.com
}

Diterima: April 2017, diterbitkan: Desember 2017

\begin{abstract}
ABSTRAK
Tujuan: Mengidentifikasi masalah penerapan fungsi pengendalian mutu dan mengembangkan solusi pemecahan masalah di ruang rawat inap. Metode: Metode yang digunakan analisis hasil dan gap implementasi menggunakan kajian literatur. Permasalahan dianalisis menggunakan diagram fishbone. Penyelesaian masalah menggunakan tools Plan Do Study Action (PDSA). Data diambil melalui wawancara terstruktur, survei, dan observasi lapangan pada 11 responden kepala ruangan dan 88 staf perawat pada tanggal 19-27 Oktober 2017. Data dianalisis secara deskriptif dengan melihat distribusi frekuensi persepsi kepala ruangan dan staf tentang pengendalian mutu dan pelaksanaan fungsi manajemen dalam pengendalian mutu. Hasil: Fungsi pengendalian mutu keperawatan belum dilaksanakan optimal pada tahap perencanaan, pemantauan dan tindak lanjut masalah (45,45\%). Implementasi penyelesaian dalam bentuk sosialisasi dan workshop yaitu panduan, prosedur, kamus dan instrumen pemantauan indikator mutu keperawatan. Hasil evaluasi menunjukkan 62\% Kepala Ruangan meningkat pengetahuannya tentang pengendalian mutu dengan rata-rata skor pre-post test meningkat 1,33 poin dari 6,10 menjadi 7,43. Survei pasca implementasi menghasilkan persepsi yang baik dari 86,67\% Kepala Ruangan mengenai pengendalian mutu keperawatan. Diskusi: Program pengendalian mutu merupakan salah satu fungsi utama kepala ruangan. Rumah sakit telah memiliki program pengendalian mutu yang dipersyaratkan standar akreditasi rumah sakit, namun kepatuhan penerapannya masih perlu dipertahankan. Rumah sakit dipersyaratkan untuk dapat mempertahankan kepatuhan dan kesinambungan pengendalian mutu guna mengevaluasi proses kerja secara berkelanjutan. Kesimpulan: Sosialisasi mengenai penerapan pengendalian mutu keperawatan cukup efektif meningkatkan pengetahuan kepala ruangan dan tentang program mutu yang dipersyaratkan akreditasi rumah sakit. Pimpinan rumah sakit perlu memberi pengakuan, dukungan, dan motivasi bagi kepala ruangan penerapan pengendalian mutu keperawatan di ruangan rawat.
\end{abstract}

Kata Kunci: fungsi manajemen, mutu keperawatan, pengendalian mutu, perawat manajer.

\section{IMPLEMENTATION OF MANAGEMENT FUNCTION OF HEAD OF WARD IN NURSING QUALITY CONTROL \\ ABSTRACT}

Objective: To identify problems in implementing quality control functions and develop solutions to problems in the inpatient ward. Method: The research employed results analysis and implementation gap by using literature review. Problems were analyzed using fishbone diagram. Problem were solved using Plan Do Study Action (PDSA) tools. Data were taken through structured interviews, surveys, and field observations in 11 heads of ward and 88 nursing staff between 19 and 27 October 2017. Data were analyzed descriptively by identifying the frequency distribution of the perception of head nurse and staff regarding quality control and the implementation of management functions in quality control. Results: The function of nursing quality control was not optimally implemented at the stages of planning, monitoring and follow-up of the problem 
(45.45\%). The solutions were implemented in the form of socialization and workshops, including guidelines, procedures, dictionaries and monitoring instruments for nursing quality indicators. The results of evaluation indicated that the average score of pre-posttest on knowledge about quality control increased by 1.33 points 6.10 to 7.43 in $62 \%$ of the Heads of Ward. The post-implementation survey produced a good perception in $86.67 \%$ of the Head of the Ward regarding the nursing quality control. Discussion: The quality control program is one of the primary functions of the head of ward. The hospital has had a quality control program that is required by hospital accreditation standards, but it should maintain the adherence of its application. Hospitals are required to maintain adherence and sustainability of quality control in order to evaluate the sustainable work process. Conclusion: The socialization of the application of nursing quality control is quite effective in increasing the knowledge of the head of ward. In regard to the program of quality required by the hospital accreditation, the board of hospital management should give recognition, support, and motivation for the heads of ward to implement nursing quality control in the nursing ward.

Keywords: management function, nursing quality, quality control, nurse- manager.

\section{LATAR BELAKANG}

Mutu pelayanan keperawatan merupakan cerminan mutu pelayanan kesehatan. Mutu adalah tingkat layanan kesehatan yang konsisten dengan pengetahuan profesional yang diperbarui dan memungkinkan diperolehnya hasil yang diinginkan (Mudallal et al., 2017; Needleman \& Hassmiller, 2009). Mutu rumah sakit dinilai sangat penting untuk dipertahankan dan ditingkatkan agar tumbuh rasa percaya masyarakat terhadap pelayanan rumah sakit tersebut. Penelitian kualitatif tentang persepsi pasien terhadap mutu keperawatan menyatakan bahwa pelayanan keperawatan merupakan pondasi dari pelayanan kesehatan dan berdampak pada pemulihan kesehatan pasien (Rehan et al., 2015). Hasil penelitian lainnya menyatakan harapan pasien terhadap pelayanan keperawatan agar terus ditingkatkan (Muhidin, Sahar, \& Wiarsih, 2010).

Undang-Undang Republik Indonesia nomor 44 Tahun 2009 tentang Rumah Sakit, pasal 29 menyatakan setiap rumah sakit wajib memberi pelayanan yang aman dan bermutu-(Kementerian HAM RI, 2009). Kewajiban rumah sakit untuk memberikan pelayanan yang aman, bermutu, dan efektif menuntut komitmen manajerial rumah sakit untuk mempertahankan pelayanan yang sesuai dengan standar. Pelayanan terstandar tersebut harus dilaksanakan setiap staf rumah sakit termasuk staf keperawatan. Mengutip Undang-Undang Keperawatan nomor 38 pasal 37, bahwa Perawat dalam melaksanakan praktik keperawatan berkewajiban: b. memberikan pelayanan keperawatan sesuai dengan kode etik, standar praktik keperawatan, standar profesi, standar prosedur operasional dan ketentuan Peraturan Perundang-undangan (Kementerian HAM RI, 2014). Standar yang menjadi acuan adalah standar mutu pelayanan sesuai ketentuan akreditasi dan kebijakan yang ditetapkan pimpinan. Standar Peningkatan Mutu dan Keselamatan Pasien mempersyaratkan bahwa rumah sakit hendaknya mempunyai referensi terkini tentang peningkatan mutu dan keselamatan pasien berdasarkan ilmu pengetahuan dan informasi terkini serta perkembangan konsep peningkatan mutu dan keselamatan pasien (Komisi Akreditasi Rumah Sakit, 2017). Pimpinan rumah sakit harus secara terus menerus berupaya menciptakan peningkatan mutu yang merupakan proses menciptakan lingkungan di mana setiap individu berusaha menciptakan mutu agar terus meningkat (Raines, 2012).

Upaya untuk meningkatkan mutu pelayanan keperawatan menuntut seluruh komponen rumah sakit bersama pimpinan/ manajer rumah sakit untuk selalu 
meningkatkan pengetahuan dan wawasan terkait mutu. Perkembangan pengetahuan terkait mutu dan keselamatan harus selalu diikuti oleh seorang manajer. Pentingnya peran manajer perawat dalam peningkatan dan penjaminan mutu rumah sakit dibuktikan dalam sebuah studi yang menyatakan kepemimpinan keperawatan mempunyai pengaruh langsung dan signifikan terhadap mutu keperawatan (Mendes \& Fradique, 2014).

Manajemen keperawatan merupakan proses perencanaan, pengorganisasian, pengaturan staf, pengarahan, dan pengendalian yang satu sama lain saling terkait. Peran manajer keperawatan tidak terlepas dari proses manajemen yang dilakukan, termasuk menerapkan perhatian kepada sumber daya material maupun sumber daya manusia keperawatan. Peran manajer yang diterapkan secara nyata mampu membawa transformasi bagi staf keperawatan lainnya untuk menerapkan standar mutu keperawatan (Huber, 2014; Kelloway, Barling, \& Helleur, 2000). Standar ditetapkan untuk mengukur performa asuhan dan pelayanan keperawatan yang bersifat obyektif, dapat diukur, dan dapat dicapai (Marquis \& Huston, 2015).

Keterlibatan staf keperawatan dalam program mutu dan peningkatan keselamatan pasien harus menjadi pertimbangan utama dari manajer keperawatan. Suatu pelayanan keperawatan sangat mungkin bermutu tinggi dengan adanya peran staf keperawatan yang merupakan pemberi pelayanan keperawatan secara langsung. Keterlibatan staf dalam program peningkatan dan pengendalian mutu merupakan syarat standar akreditasi rumah sakit yang mutlak dipenuhi rumah sakit (Joint Commission International, 2017; Komisi Akreditasi Rumah Sakit, 2017). Pengendalian mutu akan memberikan umpan balik kepada staf untuk melakukan perbaikan layanan serta penyempurnaan yang berkelanjutan (Hariyati, 2014; Marquis \& Huston, 2015).

Pengendalian mutu keperawatan di ruang rawat, pada umumnya telah dilaksanakan terutama pada rumah sakit yang akan dan sedang dilakukan akreditasi termasuk salah satu rumah sakit militer di Jakarta. Rumah sakit ini memiliki kinerja pelayanan berupa Bed Occupancy Rate (BOR) dengan rata-rata pada September 2016 sampai September 2017 adalah 79,47\%, dan Average Length Of Stay (AvLOS) 5,69 hari. BOR yang cukup tinggi tersebut memerlukan kekuatan SDM kesehatan dan administrasi yang handal untuk melaksanakan pelayanan yang bermutu. Jumlah tenaga perawat hingga Oktober 2017 sebanyak 1134 orang yang tersebar di beberapa instalasi dan unit. Rumah sakit ini meraih akreditasi internasional pada tahun 2014 dan telah melaksanakan triennial survey reakreditasi pada Oktober 2017, sedangkan focus triennial survey akan dilaksanakan pada Februari 2018 mendatang. Salah satu yang perlu menjadi perhatian dalam survei tersebut adalah belum optimalnya peningkatan mutu secara berkesinambungan mulai dari analisis masalah sampai dengan rencana tindak lanjut.

Beberapa indikator ditetapkan untuk mengukur mutu rumah sakit, indikator tersebut terdiri dari indikator area manajerial, area klinik, dan area International Patient Safety Goals (IPSG). Dari beberapa indikator tersebut, indikator mutu spesifik keperawatan yang dipantau adalah kejadian cedera tekan dengan hasil pada periode semester 1 tahun 2017 sebanyak 7 dari 37 pasien yang berisiko. Hasil observasi di 3 ruang rawat yaitu ruang rawat umum, bedah, dan stroke didapatkan bahwa kepala ruangan melakukan pengumpulan data sebagian besar dari indikator-indikator tersebut. Hasil wawancara dengan 11 kepala ruangan didapatkan bahwa kepala ruangan melakukan pemantauan 
indikator mutu keperawatan yang dilaporkan setiap bulan kepada bidang keperawatan dan komite mutu rumah sakit, namun hasil capaian indikator belum dianalisis secara optimal dan tidak diinformasikan ke staf di ruang rawat. Penyelesaian masalah belum dilakukan secara terstruktur berdasarkan capaian indikator. Fungsi pengendalian mutu keperawatan serta monitoring dan evaluasi dinyatakan oleh 6 dari 11 kepala ruangan (54\%) belum dijalankan dengan baik oleh kepala ruangan.

Kepala Bagian Keperawatan dalam wawancara menyatakan bahwa indikator keperawatan yang dipantau belum menggambarkan aspek struktur, proses dan outcome dari asuhan dan pelayanan keperawatan. Pelaksanaan fungsi pengendalian mutu keperawatan yang belum berjalan optimal ini kemungkinan juga dipengaruhi oleh struktur di rumah sakit militer dimana Kepala Bagian Keperawatan yang bertanggung jawab terhadap penjaminan mutu asuhan dan pelayanan keperawatan, kedudukannya tidak sejajar dengan Kepala Instalasi rawat inap, akan tetapi berada setingkat di bawah Kepala Instalasi. Struktur ini memungkinkan Bagian Keperawatan kurang kuat kedudukannya terhadap Kepala Instalasi termasuk peran dalam menjamin mutu asuhan keperawatan secara optimal.

Rumah sakit dalam melakukan penjaminan mutu telah melakukan upaya perbaikan berkelanjutan untuk meningkatkan pelayanan. Penyelesaian masalah pelayanan telah dilakukan menggunakan alur Plan Do Study Action (PDSA), akan tetapi cara penyelesaian ini belum tersosialisasi dengan baik dan menjadi budaya peningkatan mutu di ruang rawat yang melibatkan kepala ruangan beserta staf.

Permasalahan terkait fungsi pengendalian mutu keperawatan yang merupakan salah satu fungsi penting dalam manajemen keperawatan menjadi fokus perbaikan yang disusun bersama Bagian Keperawatan. Tujuan dari penulisan ini adalah untuk mengidentifikasi dan menganalisis masalah terkait pelaksanaan pengendalian mutu keperawatan di ruang rawat dan mengembangkan solusi pemecahan masalah dengan menggunakan pendekatan proses 5 fungsi manajemen yaitu perencanaan, pengorganisasian, ketenagaan, pengarahan, dan pengendalian.

\section{METODE}

Metode yang digunakan mini project, analisis hasil dan gap implementasi dengan pembahasan berdasarkan kajian literatur. Kegiatan dimulai dari identifikasi masalah, kemudian dilanjutkan dengan analisis masalah, penetapan prioritas masalah, penyusunan plan of action, implementasi, serta evaluasi struktur, proses dan hasil. Ruang rawat yang digunakan adalah instalasi rawat inap yang terdiri dari ruang perawatan umum, ruang bedah, unit stroke, ruang rawat khusus paru dan jantung. Dasar pemilihan ruang rawat inap merupakan ruang pelayanan pasien selama 24 jam sehingga kontak perawat dengan pasien lebih banyak. Ruang rawat inap juga merawat pasien yang cukup banyak dengan kasus dan masalah yang kompleks.

Pengambilan data dilakukan melalui wawancara terstruktur, survei melalui kuisioner, dan observasi lapangan. Data tentang peran dan fungsi top manajer, diambil melalui wawancara terhadap Kepala Bagian Keperawatan. Selain wawancara, metode observasi dilakukan untuk mengidentifikasi ketersediaan dan keterkinian dokumen yang diproduksi Bagian Keperawatan untuk pelaksanaan pengelolaan mutu keperawatan berupa Rencana Kinerja Tahunan, panduan dan standar prosedur operasional terkait pengendalian mutu keperawatan, kamus 
indikator, formulir pengumpulan dan validasi data, rekapitulasi, analisis data, analisis akar masalah dari indikator yang belum tercapai, bukti tindak lanjut dan PDSA sebagai penyelesaian masalah.

Data tentang fungsi manajemen keperawatan di ruang rawat diambil dari wawancara terstruktur, observasi dan survei kuisioner. Observasi lapangan dilakukan di tiga ruang rawat yaitu ruang perawatan umum, bedah, dan stroke untuk mengidentifikasi penerapan pengendalian mutu keperawatan dan ketersediaan dokumen yang mendukung. Wawancara terstruktur dilakukan secara kelompok terdiri dari sepuluh kepala ruangan yang mewakili ruang perawatan umum, ruang rawat bedah, ruang rawat anak, dan ruang rawat khusus jantung, bertujuan untuk menggali persepsi kepala ruangan tentang peran dan fungsi pengendalian mutu keperawatan di ruang rawat. Penjelasan tentang tujuan dan topik wawancara diberikan sebelum wawancara, dilanjutkan dengan penandatanganan lembar persetujuan untuk wawancara. Alat bantu yang digunakan berupa panduan berisi pertanyaan yang bersifat terbuka, serta alat perekam menggunakan handphone untuk mendokumentasikan hasil wawancara.

Survei melalui kuesioner dilakukan terhadap kepala ruangan dan staf. Sampel kepala ruangan adalah total sampling dengan jumlah yang bersedia menjadi responden sebanyak 11 orang dari Instalasi Rawat Inap. Sampel perawat pelaksana menggunakan rumus rules of thumb yaitu $n>50+8 m$, sehingga didapatkan sebanyak 114 perawat (Thabane, 2004; Thabane et al., 2010). Rumus ini dipilih karena mempertimbangkan waktu pengambilan data yang sangat singkat sehingga sampel yang diambil tidak besar. Kuisioner yang kembali sebanyak 88 kuisioner, sedangkan 26 kuesioner tidak kembali karena waktu kegiatan yang terbatas dan hingga batas waktu yang ditetapkan kuesioner tersebut tidak dikembalikan.

Kuisioner diadaptasi dari tools yang dikembangkan oleh The Agency for Healthcare Research and Quality (AHRQ) pada tahun 2008. AHRQ merancang 24 jenis tools yang dapat digunakan untuk menilai penerapan peningkatan mutu. Salah satu too/s tersebut adalah untuk menilai peran dan kesiapan organisasi dalam upaya meningkatkan mutu (The Agency for Healthcare Research and Quality, 2008). Kuisioner dimodifikasi beberapa pernyataannya menggunakan alur 5 fungsi manajemen (perencanaan, pengorganisasian, ketenagaan, pengarahan, dan pengendalian). Kuisioner berisi pernyataan terkait peran kepala ruangan dan staf perawat dalam penerapan pengendalian mutu keperawatan, fungsi manajemen kepala ruangan dan dukungan rumah sakit. Pengambilan data diawali dengan penjelasan kepada calon responden, dilanjutkan dengan penandatanganan lembar persetujuan pengumpulan data bagi yang bersedia menjadi responden.

Data dianalisis secara deskriptif dengan melihat distribusi frekuensi persepsi kepala ruangan dan staf tentang pengendalian mutu dan pelaksanaan fungsi manajemen dalam pengendalian mutu. Hasil wawancara digunakan sebagai pendukung dalam melakukan analisis data. Hasil analisis data digunakan dalam penetapan masalah yang diidentifikasi menggunakan diagram fishbone. Penyelesaian masalah dari mulai penetapan Plan of Action (POA), implementasi, evaluasi, dan tindak lanjut. Penyusunan POA dilakukan bersama Bagian Keperawatan dan kepala ruangan melalui brain storming dan diskusi terarah. Rencana tindakan disusun mengikuti alur fungsi manajemen sesuai hasil asesmen pada tiap fungsi dan diimplementasikan bersama. Evaluasi dilakukan terhadap 5 kepala ruangan atau penanggung jawab 
mutu dari ruang perawatan umum dan bedah. Evaluasi menggunakan kuisioner dan observasi langsung yang dilakukan bersamaan dengan pendampingan dan simulasi analisis masalah mutu.

\section{HASIL}

\section{Asesmen dan Analisis Masalah}

Hasil penulisan ini akan diuraikan berdasarkan hasil survei melalui kuesioner dengan sekaligus ditambahkan dari hasil wawancara dan observasi sebagai data pendukung.
Hasil survei melalui kuisioner menunjukkan persepsi kepala ruangan terhadap tindak lanjut perbaikan masalah mutu dilakukan dengan baik oleh 45\% kepala ruangan (gambar 1). Staf belum semua mendapatkan informasi hasil capaian mutu sehingga kurang optimal dalam keikutsertaan melakukan upaya perbaikan (gambar 2). Data pendukung dari hasil wawancara kepala ruangan menyatakan belum optimalnya tindak lanjut dari hasil capaian mutu.

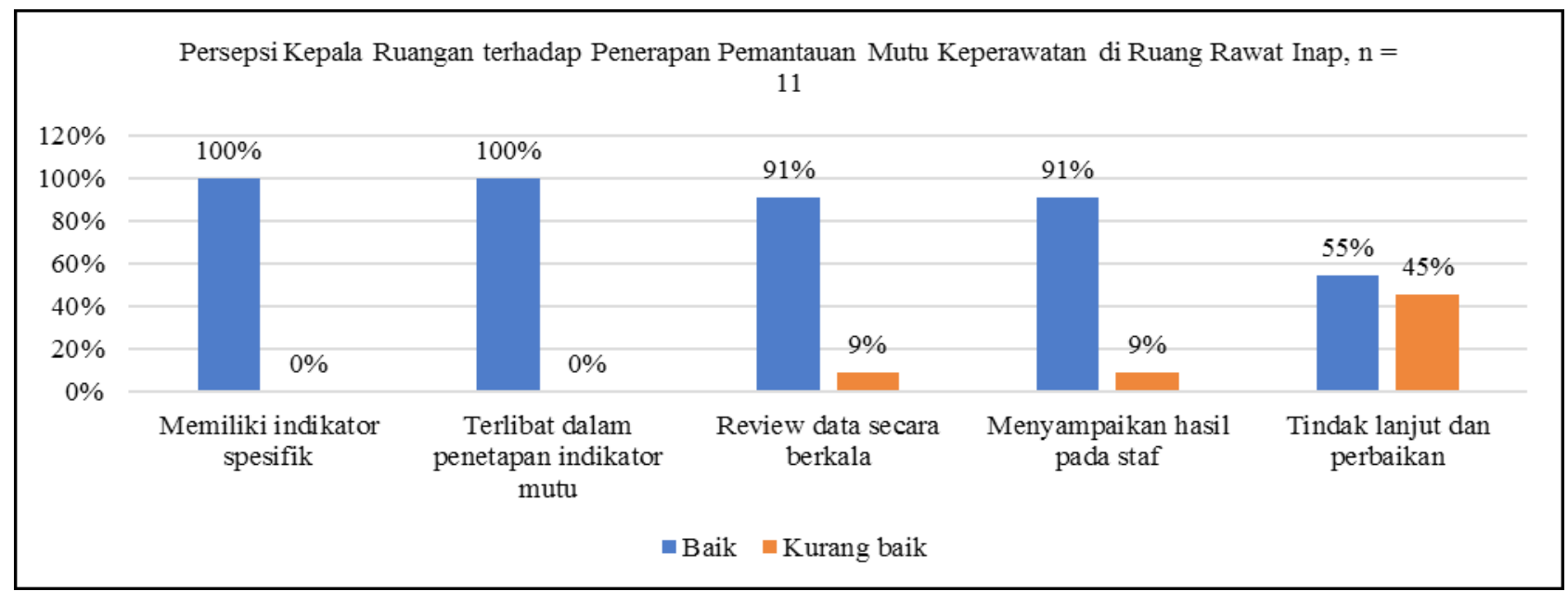

Gambar 1. Persepsi Kepala Ruangan terhadap penerapan pemantauan mutu keperawatan

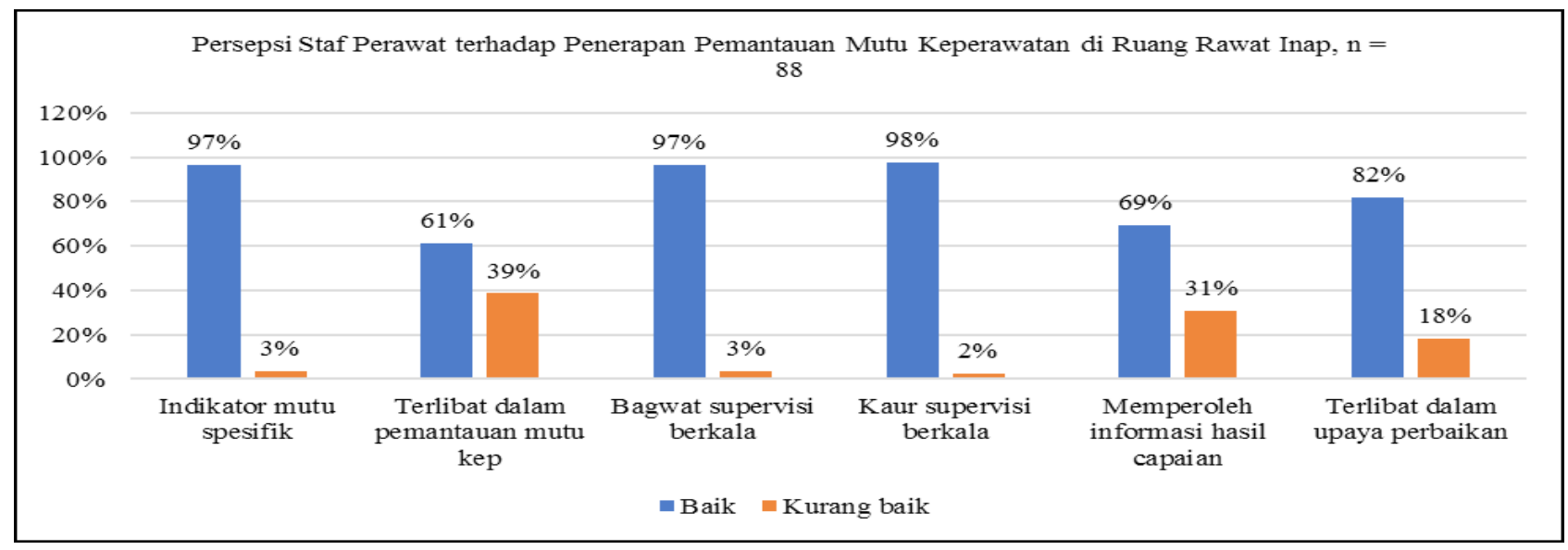

Gambar 2. Persepsi Staf Perawat terhadap penerapan pemantauan mutu keperawatan 
Hasil wawancara seluruh kepala ruangan menyatakan belum dilibatkan secara optimal dalam penetapan indikator mutu untuk ruang rawat yang dikelolanya, sama dengan staf perawat yang merasa belum dilibatkan dalam pemantauan dan upaya tindak lanjut hasil indikator. Berdasarkan wawancara terstruktur, 45\% Kepala Ruangan belum memahami definisi dari masing-masing indikator mutu yang dipantau, analisis data hasil capaian secara berkala dan penyampaian hasil kepada staf perawat yang belum optimal. Peran Kepala Ruangan hanya sebatas mengumpulkan data, menginput dan mengirimnya ke Komite mutu rumah sakit. Data yang dikumpulkan tidak divalidasi untuk menjamin kredibilitas data.

Hasil survei terkait fungsi manajemen kepala ruangan teridentifikasi fungsi perencanaan, pengarahan dan pengendalian terkait penerapan indikator mutu keperawatan masih perlu ditingkatkan (gambar 4). Standar Operasional Prosedur belum tersosialisasi dengan baik dan staf perawat belum dilibatkan secara optimal dalam pengendalian mutu. Hasil wawancara Kepala Ruangan belum memahami definisi indikator yang dipantau karena belum aware dengan kamus indikator. Hasil observasi langsung di ruang rawat inap $A$ dan $B$, pengisian beberapa formulir pemantauan belum dapat dimengerti. Fungsi pengarahan dalam hal pelaksanaan supervisi belum berjalan secara rutin dan tindak lanjut capaian mutu belum optimal (45,45\%). Fungsi pengendalian, monitoring dan evaluasi indikator mutu keperawatan belum berjalan dengan baik $(45,55 \%)$.

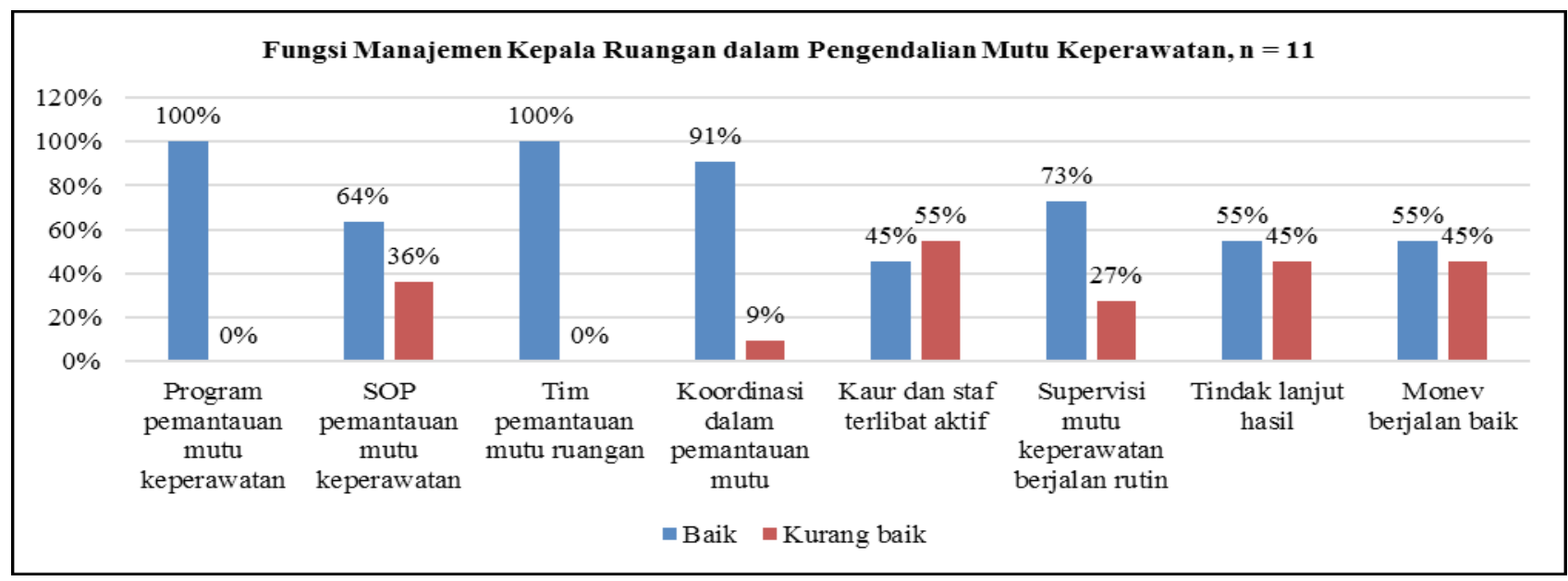

Gambar 4. Fungsi manajemen Kepala Ruangan dalam pengendalian mutu keperawatan

Masalah yang ditemukan dari hasil asesmen, dianalisis menggunakan diagram fishbone yang merupakan analisis masalah dengan pendekatan analisis sebab akibat (gambar 5). Hasil analisis masalah ditemukan belum optimalnya pelaksanaan pengendalian mutu keperawatan dari mulai perencanaan sampai pengontrolan. Panduan belum diupdate sesuai kebutuhan saat ini, demikian pula standar prosedur operasional (SPO) yang menjadi acuan dalam pelaksanaan pengendalian mutu keperawatan beserta formulir atau instrumen yang diperlukan untuk pengambilan data. Panduan yang belum difahami menyebabkan ketentuan pengumpulan dan validasi data mutu tidak dilaksanakan dengan baik. Tindak lanjut masalah mutu yang seharusnya dilakukan oleh Kepala Ruangan tidak dapat dilaksanakan secara optimal karena sistem supervisi belum terstruktur dan terjadwal. 


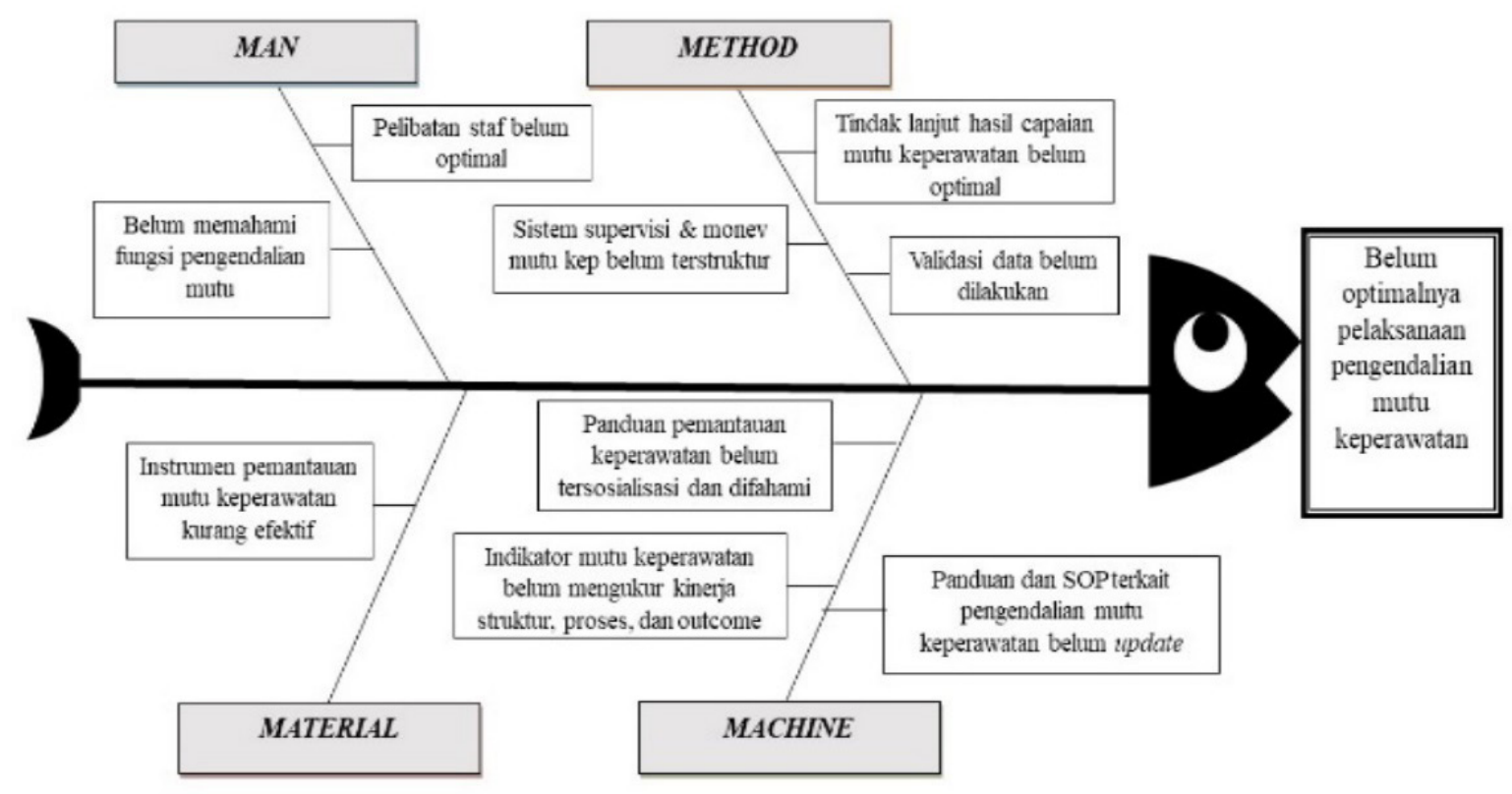

Gambar 5. Analisis masalah pengendalian mutu keperawatan menggunakan fishbone

\section{Implementasi}

Hasil analisis fishbone menjadi dasar dalam menyusun rencana tindak lanjut. Rencana tindak lanjut menggunakan kerangka POSAC yaitu fungsi manajemen keperawatan dari mulai perencanaan, pengorganisasian, ketenagaan, pengarahan, dan pengendalian/ pengontrolan. Pendekatan ini diharapkan dapat secara langsung memberikan solusi masalah pengelolaan mutu keperawatan dan mengoptimalkan fungsi manajemen oleh Bagian Keperawatan dan Kepala Ruangan.

Pada fungsi perencanaan, implementasi yang dilakukan adalah pengembangan dan penyusunan dokumen berupa Panduan Pengendalian Mutu Keperawatan dan Standar Prosedur Operasional yang disertai lampiran berupa kamus dan formulir pemantauan. Panduan disusun oleh Bagian Keperawatan dengan melibatkan Kepala Ruangan dan Penanggung Jawab Mutu ruangan. Draft panduan dan SPO disampaikan dalam sosialisasi dan workshop, dimana pada kegiatan ini terjadi brainstorming atau tukar pendapat antara Kepala Ruangan yang difasilitasi oleh Bagian Keperawatan. Draft dokumen tersusun $75 \%$ dan akan disempurnakan Bagian Keperawatan.

Implementasi fungsi pengorganisasian dan ketenagaan berupa usulan pembentukan tim mutu ruang rawat dicantumkan dalam panduan pengendalian mutu keperawatan. Kepala Seksi pengendalian mutu keperawatan adalah manajer level atas yang merupakan pejabat dibawah Kepala Bagian Keperawatan yang bertanggung jawab dalam penjaminan mutu keperawatan di rumah sakit. Kepala Ruangan merupakan manajer yang mengelola langsung ruang rawat yang bertanggung jawab dalam pelaksanaan peningkatan mutu keperawatan secara berkelanjutan di ruang yang dikelolanya. Penanggung jawab mutu adalah staf yang membantu Kepala Ruangan dalam melakukan pemantauan dan peningkatan mutu berkelanjutan. 
Masalah pada fungsi pengarahan, ditindaklanjuti dengan workshop dan sosialisasi panduan pengendalian mutu keperawatan dihadiri 11 kepala ruangan dan 10 penanggung jawab mutu ruangan. Kegiatan ini bertujuan melakukan sosialisasi dan diskusi draft panduan. Kepala ruangan diberikan pengarahan tentang pengendalian mutu keperawatan yang difokuskan pada pemantapan pemahaman indikator mutu keperawatan yang mencakup keselamatan, kenyamanan, pengetahuan, kecemasan, kepuasan pasien, dan perawatan diri. Indikator mengadopsi dari JCl Library dan Nursing Sensitive Indicator dari American Nursing Association (ANA). Kepala Ruangan juga diberikan materi mengenai analisis data, analisis masalah dan tindak lanjut hasil. Kegiatan pengarahan dilanjutkan dengan pendampingan dan simulasi tentang analisis masalah di 2 ruang perawatan umum dan 3 ruang perawatan bedah.

Implementasi untuk fungsi pengendalian dan pengontrolan, dilakukan penetapan indikator berdasarkan kebutuhan pelayanan keperawatan dan kemudahan dalam memantau serta tidak duplikasi dengan indikator yang diukur komite mutu rumah sakit. Indikator yang disepakati adalah kejadian luka tekan (aspek keselamatan pasien), persentase kepatuhan tata laksana nyeri oleh perawat (aspek kenyamanan) dan persentase pemenuhan perawatan diri pasien (aspek self care). Dasar pemilihan indikator ini adalah adanya kriteria high risk, high volume, dan bad performance. Selain itu, kondisi di ruang rawat dan beban kerja Kepala Ruangan juga menjadi pertimbangan. Implementasi untuk mengoptimalkan pelaksanaan monitoring dan evaluasi adalah dengan menyusun draft sistem supervisi dan pemantauan mutu keperawatan secara internal dan lintas ruang.

\section{Evaluasi}

Evaluasi dilakukan pasca workshop dan sosialisasi panduan melalui pre dan post test dengan menjawab 10 butir soal pilihan ganda tentang fungsi pengendalian mutu keperawatan. Nilai rata-rata pre dan post test peserta meningkat dari rata-rata 6,10 menjadi 7,43 atau meningkat 1,33 poin (gambar 6 dan 7). Jumlah kepala ruangan yang meningkat nilainya lebih banyak dari jumlah penanggung jawab mutu. Dalam kegiatan workshop tersebut kepala ruangan menyampaikan pendapatnya yaitu kegiatan workshop ini menambah pengetahuan dan wawasan dalam menjalankan fungsi manajemen terutama fungsi pengendalian mutu keperawatan. Kepala ruangan menyampaikan harapannya agar Bagian Keperawatan memberikan pengarahan dan pendampingan secara berkala dalam penerapan penjaminan mutu keperawatan.

Evaluasi juga dilakukan setelah pendampingan dan simulasi pembuatan analisis masalah dan rencana tindak lanjut. Evaluasi bertujuan untuk menggali persepsi kepala ruangan dan penanggung jawab mutu setelah workshop, sosialisasi dan simulasi tentang pengendalian mutu keperawatan. Responden mengisi lembar kuesioner yang berisi 6 pernyataan mengenai pemantauan mutu keperawatan, analisis masalah dan tindak lanjut hasil, serta pertanyaan terbuka untuk menggali perasaan setelah melakukan simulasi analisis masalah dan menggali harapan dalam penerapan pengendalian mutu. 


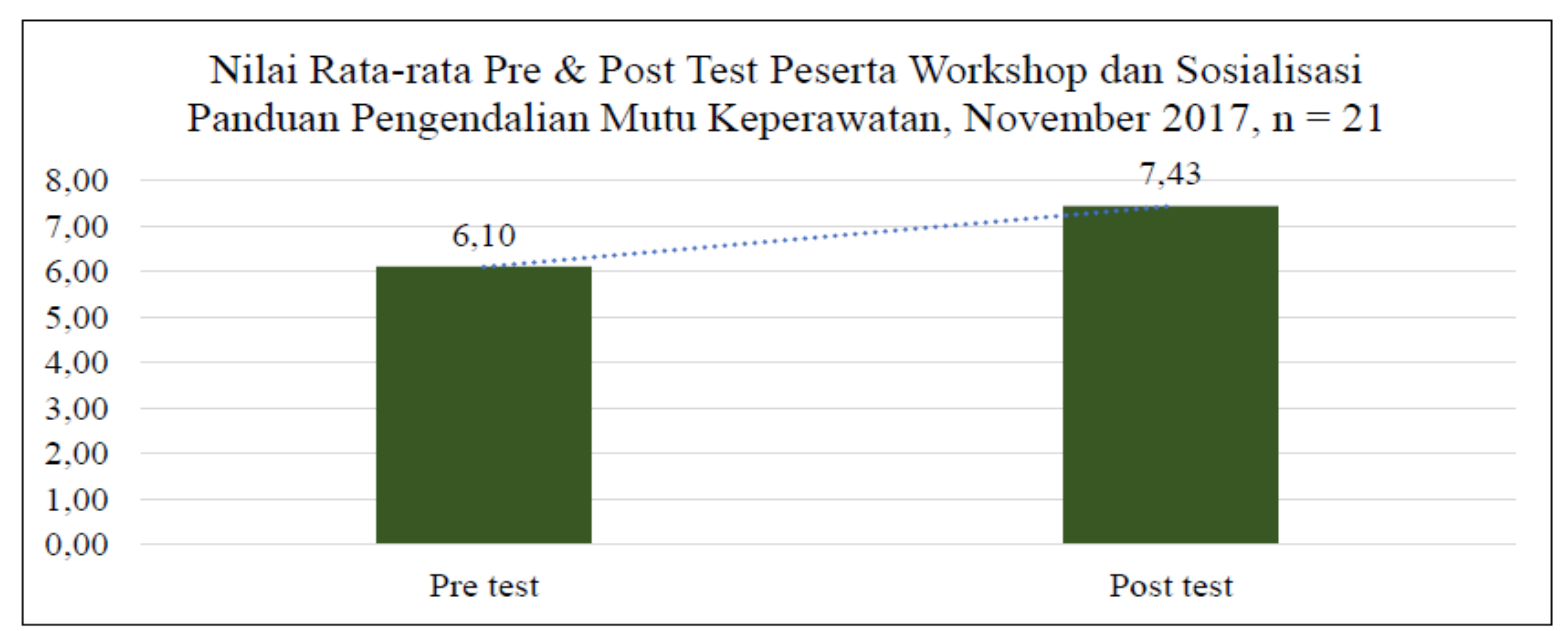

Gambar 6. Nilai rata-rata pre \& post test peserta workshop

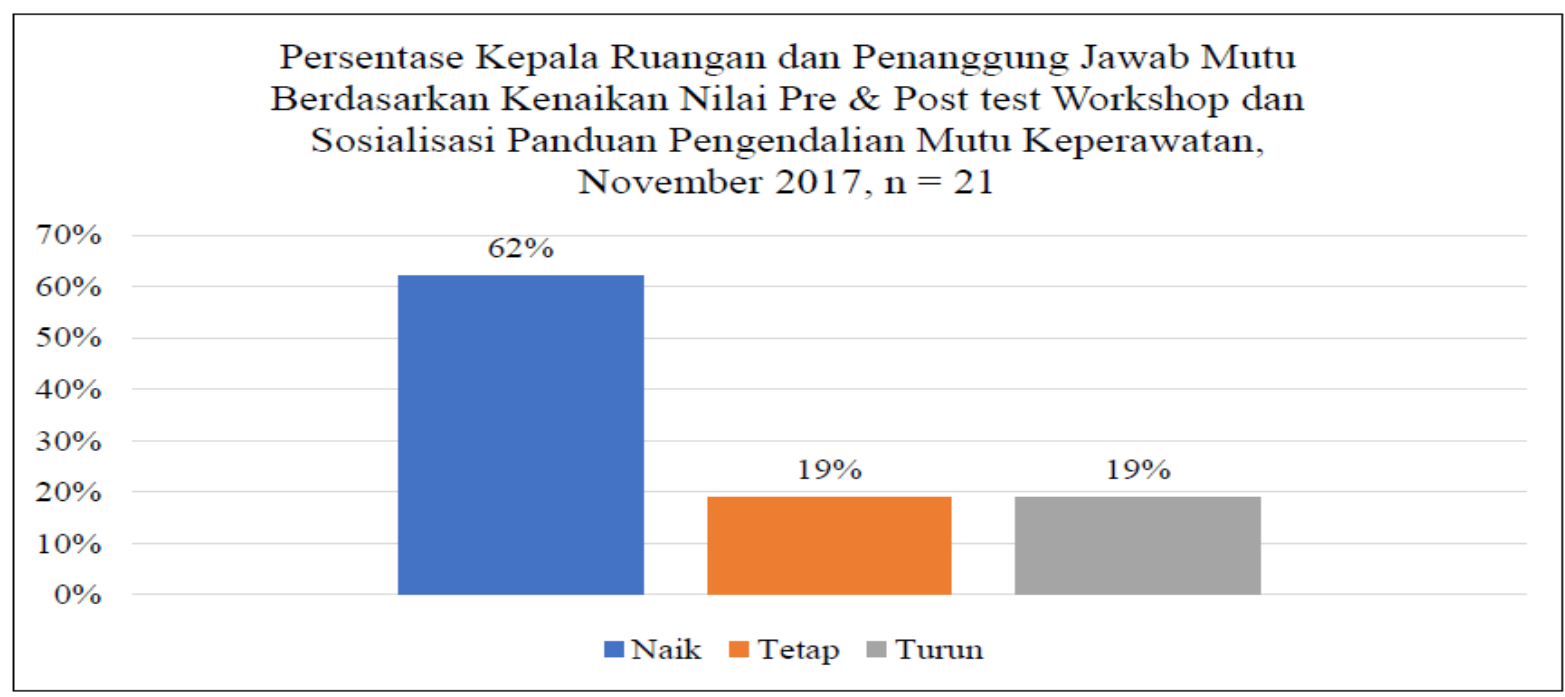

Gambar 7. Persentase Kepala Ruangan berdasarkan nilai pre \& post test

Tabel 1. Persepsi Kepala Ruangan pasca workshop dan simulasi Pengendalian Mutu Keperawatan

\begin{tabular}{clcc}
\hline No & Pernyataan & Baik & Kurang \\
\hline 1 & $\begin{array}{l}\text { Fungsi pengendalian mutu keperawatan sangat penting untuk } \\
\text { dilaksanakan }\end{array}$ & $100 \%$ & $0 \%$ \\
\hline 2 & Monitoring dan evaluasi mutu keperawatan sudah berjalan dengan baik & $40 \%$ & $60 \%$ \\
\hline 3 & Indikator mutu prioritas dapat mengukur mutu layanan di ruang rawat & $100 \%$ & $0 \%$ \\
\hline 4 & Analisis hasil capaian menjadi dasar untuk mengidentifikasi masalah & $100 \%$ & $0 \%$ \\
\hline 5 & $\begin{array}{l}\text { Melakukan analisis masalah dapat memudahkan dalam menentukan } \\
\text { tindak lanjut dan perbaikan }\end{array}$ & $100 \%$ & $0 \%$ \\
\hline 6 & $\begin{array}{l}\text { Rencana tindak lanjut menjadi panduan untuk melakukan upaya } \\
\text { perbaikan }\end{array}$ & $80 \%$ & $20 \%$ \\
\hline
\end{tabular}


Tabel 2. Pendapat Kepala Ruangan tentang Penerapan Pengendalian Mutu Keperawatan

\begin{tabular}{ll}
\hline No & Pertanyaan terbuka dan Pendapat \\
\hline 1 & Perasaan setelah melakukan simulasi analisis dan tindak lanjut masalah mutu keperawatan: \\
& $40 \%$ merasa lebih memahami, $40 \%$ merasa lebih mudah melaksanakan, $20 \%$ menyatakan \\
& dapat memperbaiki masalah \\
\hline $2 \quad$ & Harapan terhadap penerapan pengendalian mutu keperawatan: \\
& $40 \%$ menyatakan harapan agar pengendalian mutu berjalan optimal sampai tindak lanjut \\
& dan evaluasi, $40 \%$ berharap agar quality improvement berkelanjutan untuk memberi \\
& pelayanan keperawatan lebih baik, $20 \%$ menyatakan harapan agar semua staf terlibat dalam \\
& pengendalian mutu \\
\hline $3 \quad$ Saran dan komentar: \\
Hasil analisis dapat mudah diakses dan tidak ada duplikasi data \\
Agar diberi penjelasan secara detail tentang formulir pemantauan mutu \\
Supervisi dari Bagian Keperawatan dan Tim mutu RS setiap minggu \\
Adanya pendampingan berkala dari jajaran manajemen rumah sakit dalam pelaksanaan \\
pengendalian mutu keperawatan di rumah sakit \\
Agar dilakukan edukasi petunjuk pengumpulan data \\
\hline
\end{tabular}

Hasil evaluasi didapatkan ratarata kepala ruangan memiliki persepsi yang positif $(86,67 \%)$ setelah diberikan sosialisasi, workshop, dan simulasi (tabel 1). Seluruh kepala ruangan menyatakan pentingnya pengendalian mutu keperawatan dalam pengelolaan ruang rawat, namun pelaksanaan monitoring dan evaluasi serta tindak lanjut pemantauan mutu dirasakan belum optimal (40\%). Hasil survei kuisioner pertanyaan terbuka dapat dilihat pada tabel 2 dimana dapat disimpulkan bahwa kepala ruangan merasa lebih memahami dan lebih mudah melaksanakan langkah pengendalian mutu keperawatan. Kepala ruangan menyampaikan harapan agar dokumen penunjang pelaksanaan pengendalian mutu mudah difahami dan mampu laksana. Secara umum kepala ruangan mengharapkan penerapan pengendalian mutu berjalan optimal serta dapat melakukan tindak lanjut untuk perbaikan berkesinambungan.

\section{DISKUSI}

Bagian ini membahas hasil yang dikaitkan dengan literatur dan beberapa hasil penelitian. Pembahasan mengikuti alur fungsi manajemen keperawatan yaitu perencanaan, pengorganisasian, ketenagaan, pengarahan, dan pengendalian.

Pengendalian mutu keperawatan merupakan salah satu fungsi utama kepala ruangan dalam menjalankan pengelolaan keperawatan di ruang rawat. Hasil asesmen awal dan evaluasi menunjukkan bahwa rumah sakit telah memiliki program pengendalian mutu yang dipersyaratkan oleh standar akreditasi rumah sakit, akan tetapi compliance penerapannya yang perlu dipertahankan dan dijaga. Rumah sakit dipersyaratkan secara mutlak untuk dapat mempertahankan kepatuhan dan kesinambungan penerapan mutu karena dengan menerapkan pengendalian mutu rumah sakit dapat mengevaluasi proses kerja secara kontinyu (Lucas \& Nacer, 2015; Raines, 2012). 
Beberapa penyebab yang dapat diidentifikasi dari hasil asesmen adalah belum optimalnya penerapan langkahlangkah peningkatan mutu dalam rangka meningkatkan mutu pelayanan keperawatan. Mutu pelayanan harus terus menerus dievaluasi sebagai dasar peningkatan yang berkesinambungan, karena itu proses penjaminan mutu tidak berhenti hanya sampai pengukuran saja, tetapi sampai dengan tindak lanjut dan evaluasi (Hariyati, 2014). Masalah utama dari langkah pengendalian mutu yang teridentifikasi adalah belum optimalnya perencanaan dalam pengendalian mutu dimana dokumen pendukung untuk penerapannya belum diupdate dan dikembangkan. Masalah utama lain adalah belum optimalnya tindak lanjut hasil pemantauan, sehingga data yang dikumpulkan tidak menjadi manfaat yang besar untuk perbaikan pelayanan. Standar akreditasi Joint Commission International edisi 6 pada bab Quality improvement and Patient Safety (QPS) pasal 8 menyatakan bahwa data yang dikumpulkan harus selalu dianalisis agar tren yang tidak diinginkan dapat teridentifikasi dan ditindaklanjuti (Joint Commission International, 2017).

Hasil implementasi untuk mengoptimalkan fungsi pengendalian mutu keperawatan mendapat dukungan penuh dari Bagian Keperawatan dan kepala ruangan. Panduan dan standar operasional prosedur (SPO) yang disusun bersama, menjadi langkah awal kepala ruangan untuk memahami proses pengendalian mutu keperawatan. Kepala ruangan dalam melaksanakan tugasnya memerlukan dokumen kebijakan sebagai acuan dalam melaksanakan pengendalian mutu keperawatan. Dokumen terdiri dari panduan, standar prosedur operasional, dan formulir atau instrumen yang dibutuhkan untuk pemantauan mutu keperawatan. Dokumen kebijakan memastikan keseragaman dan konsistensi dalam pengambilan keputusan, membantu memecahkan masalah, menumbuhkan stabilitas dan kontinuitas, menyediakan kerangka kerja, dan mengklarifikasi fungsi dan tanggung jawab (NSW Goverment, 2013; Schwartz, 2017). Akreditasi rumah sakit mempersyaratkan ketersediaan dokumen yang merupakan regulasi rumah sakit dalam bentuk panduan tata naskah rumah sakit. Panduan merupakan petunjuk dalam melakukan kegiatan yang dilengkapi dengan SPO untuk memastikan ketepatan dalam mengimplementasikan suatu kegiatan (Komisi Akreditasi Rumah Sakit, 2012).

Draft indikator yang dipilih bersama Bagian Keperawatan diusulkan dalam panduan pengendalian mutu keperawatan. Penetapan indikator harus melibatkan jajaran keperawatan yang ditunjuk rumah sakit. Penetapan indikator dapat merujuk pada Nursing Sensitive Indicators yang ditetapkan oleh American Nurses Association (ANA), JCI Library, dan draft pedoman pemantauan mutu keperawatan dari Kementerian Kesehatan Republik Indonesia. Indikator mutu keperawatan yang spesifik dan berbeda dengan indikator kesehatan lainnya merupakan ukuran yang mencerminkan struktur, proses, dan outcome asuhan keperawatan (Hughes, 2008; Joint Commission International, 2017; Jones, 2016; Montalvo, 2007). Indikator struktur terkait dengan operasional pelayanan keperawatan, contoh waktu asuhan keperawatan per hari pasien, rasio perawat:pasien, indikator proses terkait dengan proses asuhan keperawatan, contoh pemenuhan perawatan diri, kelengkapan dokumentasi keperawatan, sedangkan indikator outcome terkait dengan hasil asuhan keperawatan, contoh kejadian luka tekan, kejadian jatuh, infeksi rumah sakit, dan kepuasan pasien/ keluarga (Heslop \& Lu, 2014). 
Standar Quality and Patient Safety (QPS) 4 dalam akreditasi rumah sakit menyatakan bahwa data indikator mutu menggambarkan kinerja rumah sakit dan membandingkan kinerja dengan rumah sakit lain. Pengumpulan dan analisis data indikator mutu keperawatan merupakan bagian penting dari pengendalian mutu keperawatan karena data yang diperoleh menjadi dasar untuk melakukan perbaikan. Data yang dikumpukan kepala ruangan di ruang rawat belum dilakukan validasi, hal ini dapat menyebabkan data yang diperoleh kurang kredibel. Validasi data merupakan proses untuk memastikan data benar, handal, lengkap, dan relevan. QPS 6 mempersyaratkan adanya proses validasi data secara internal yang dilaksanakan rumah sakit agar data yang diperoleh tersebut benar-benar menjadi data yang dapat dipercaya kebenarannya (Joint Commission International, 2017). Proses validasi menurut standar akreditasi $\mathrm{JCl}$ detail dicantumkan dalam draft SPO validasi data mutu.

Pengambilan data indikator sebagai salah satu proses dalam pengendalian mutu keperawatan harus didukung dengan tim yang bertanggung jawab dalam peningkatan mutu di ruangan. Pelibatan staf sebagai tim pengendalian mutu menjadi salah satu yang mengkontribusi timbulnya motivasi staf untuk melakukan perbaikan berkesinambungan. Perawat merupakan kunci dalam mewujudkan mutu pelayanan yang tinggi, oleh karena itu seluruh staf harus dilibatkan dalam program peningkatan mutu, sehingga pelibatan staf tersebut dapat memberi kontribusi berupa ide atau saran yang digunakan untuk perbaikan serta mempengaruhi hasil/ outcome (Bentley, 2017; Hariyati, 2014; Neuhauser, 2011). Tim pengendalian mutu keperawatan yang dicantumkan dalam panduan dapat membantu keberlangsungan penjaminan mutu keperawatan di ruang rawat. Pembentukan tim juga dapat meningkatkan rasa tanggung jawab staf dalam peningkatan mutu keperawatan. Partisipasi aktif dari staf keperawatan akan berdampak pada kepatuhan terhadap standar, selanjutnya outcome yang diharapkan dari penerapan standar-standar tersebut adalah tercapainya tujuan asuhan pasien dan meningkatnya kepuasan pasien. Studi menyatakan bahwa mutu asuhan keperawatan menjadi alat ukur dan faktor yang mempengaruhi kepuasan pasien terutama dalam hal skill dan pengetahuan klinis perawat (Kol et al., 2018). Pengumpulan data secara silang yang direncanakan mulai Januari 2018 merupakan salah satu upaya Bagian Keperawatan untuk mengefektifkan pelaksanaan supervisi dan meningkatkan rasa saling memiliki satu sama lain antara ruang-ruang rawat, serta mengoptimalkan pelibatan kepala ruangan.

Salah satu upaya melibatkan staf dalam program pengendalian mutu keperawatan adalah melalui pemberian informasi yang jelas tentang hasil capaian indikator. Pemberian informasi hasil capaian indikator kepada staf sangat diperlukan sebagai umpan balik atas kinerja yang dicapai. Manajer keperawatan perlu memperhatikan respon staf dalam menerima umpan balik. Sebuah studi menyatakan bahwa ada 4 respon perawat dalam menerima umpan balik yaitu (1) umpan balik dianggap sebagai perintah untuk menindaklanjuti hasil pengukuran mutu; (2) umpan balik dianggap sebagai motivasi ekstrinsik yang sangat penting untuk menindaklanjuti hasil pengukuran mutu; (3) umpan balik dianggap sebagai sumber daya intrinsik memotivasi perawat untuk menindaklanjuti hasil pengukuran mutu; dan 4) umpan balik tidak dianggap sebagai permintaan pekerjaan, atau sebagai sumber pekerjaan (Giesbers et al., 2016). Staf yang berpotensi sebagai agen pembaharu dalam menerima umpan balik adalah pada poin 2 dan 3 yang dapat dioptimalkan untuk 
melakukan perubahan. Studi lain menyatakan bahwa data hasil capaian mutu harus mudah diakses dan disajikan dengan cara yang mudah dimengerti sehingga staf dapat mengidentifikasi dampak kinerjanya terhadap hasil capaian mutu dan dapat memberi ide solusi dari masalah yang ditemukan (Bentley, 2017; Joint Commission International, 2017; Zoschak, 2010). Jelasnya informasi hasil capaian indikator, dapat menjadi peluang manajer perawat untuk melibatkan staf dalam melakukan analisis akar masalah agar tindak lanjut yang disusun tepat sasaran.

Implementasi untuk menyelesaikan masalah kurang optimalnya pelaksanaan analisis dan tindak lanjut masalah dilakukan dengan simulasi penyusunan analisis akar masalah dan membuat rencana tindak lanjut. Tools yang dipilih untuk simulasi analisis akar masalah adalah fishbone analysis dan 5 why. Tools peningkatan kualitas dapat membantu dalam memberdayakan staf untuk memahami data yang dibutuhkan untuk menerapkan strategi perbaikan proses (Bentley, 2017). Perawat memiliki posisi yang baik untuk tidak hanya menganalisis data dari tindakan tetapi juga untuk merancang dan menerapkan strategi yang mempengaruhi pemberian perawatan. Banyak perawat mengkoordinasikan kegiatan di antara tim multidisiplin, dan mengatur intervensi antar departemen yang akhirnya dapat meningkatkan mutu perawatan (Farquhar, 2008). Analisis akar masalah yang menurut standar akreditasi dilakukan untuk mencari akar masalah insiden atau sentinel, dapat juga digunakan untuk mencari akar masalah dari hasil capaian indikator mutu yang tidak memenuhi target atau standar karena hal tersebut juga merupakan suatu kejadian yang tidak diinginkan. Analisis akar masalah dari hasil capaian mutu keperawatan dapat membantu kepala ruangan dalam menentukan langkah tindak lanjut yang tepat.
Kepala ruangan memerlukan arahan dan bimbingan Bagian Keperawatan untuk dapat menganalisis masalah dengan baik.

Pendampingan, bimbingan, pelatihan dan supervisi dari manajemen ke ruang rawat merupakan hal yang dibutuhkan dalam pelaksanaan standar mutu keperawatan. Hubungan yang baik antara kepala ruangan dengan manajer serta kepala ruangan dengan staf mendukung kinerja mengelola ruang rawat. Kepala ruangan beserta staf memerlukan pembekalan dan pendidikan berkelanjutan untuk meningkatkan kompetensi dan kemampuan agar dapat meerapkan penjaminan mutu dengan baik di ruangan. Sebuah telaah sistematis mengidentifikasi pendidikan merupakan faktor yang paling berpengaruh dalam meningkatkan kompetensi perawat termasuk dalam menerapkan standar mutu keperawatan (Rizany, Hariyati, \& Handiyani, 2018). Penelitian menyatakan bahwa peningkatan pengetahuan yang didapat dari pelatihan keterampilan interpersonal berpengaruh secara bermakna terhadap peran interpersonal dan kepemimpinan kepala ruangan (Suhariyanto, Hariyati, \& Ungsianik, 2018).

Supervisi dan pengarahan terhadap staf perawat dapat menumbuhkan kekuatan dan percaya diri dalam menerapkan pengendalian mutu keperawatan. Supervisi rutin secara internal dari kepala ruangan juga dapat menambah penguatan staf dan meminimalkan insiden. Sebuah penelitian menunjukkan bahwa kepemimpinan keperawatan memiliki dampak langsung dan signifikan secara statistik berpengaruh terhadap penurunan insiden dan peningkatan mutu keperawatan (Ezeukwu, 2011; Mendes \& Fradique, 2014). Penelitian lain menyatakan bahwa model kepemimpinan dan pengarahan kepala ruangan berhubungan secara bermakna dengan retensi perawat (Sigit, 
Keliat, \& Hariyati, 2011; Yasman, Sahar, \& Nuraini, 2015). Pemberdayaan staf dengan cara melibatkan aktif dalam pengendalian mutu keperawatan merupakan strategi yang tepat untuk meningkatkan pelayanan keperawatan. Sebuah studi menyatakan bahwa tipe kepemimpinan transformasional dan transaksional berhubungan erat dengan pemberdayaan staf perawat dan dapat memotivasi serta menginspirasi (Fergus, 2012; Manning, 2014; Pianella, 2014). Manajer yang menerapkan kepemimpinan transformasi, memberikan pengaruh melalui perilaku yang ideal, memotivasi dan menginspirasi, perhatian yang bersifat individu, dan memberi stimulasi intelektual. Manajer dengan tipe kepemimpinan transaksional menerapkan strategi pemberian reward dan punishment untuk memotivasi staf.

\section{SIMPULAN}

Penerapan fungsi pengendalian mutu keperawatan oleh kepala ruangan belum optimal dalam hal tindak lanjut dari hasil capaian mutu. Selain itu pelibatan kepala ruangan dalam penetapan indikator mutu keperawatan. Kurangnya pelibatan kepala ruangan tersebut berdampak pada belum difahaminya definisi dari masing-masing indikator mutu yang dipantau.

Hasil sosialisasi, workshop, dan simulasi tentang langkah dalam penerapan pengendalian mutu keperawatan cukup efektif meningkatkan pengetahuan kepala ruangan dan membuka wawasan lebih luas tentang pemantauan mutu yang dipersyaratkan akreditasi rumah sakit. Persepsi yang baik dari kepala ruangan tentang pentingnya fungsi pengendalian mutu menjadi modal awal yang baik untuk melakukan perubahan dan perbaikan dalam menjalankan fungsinya. Pengendalian mutu keperawatan merupakan salah satu fungsi utama manajemen keperawatan. Fungsi ini memerlukan dukungan rumah sakit dalam penerapannya terutama dalam tahap perencanaan dimana program pengendalian mutu keperawatan membutuhkan dokumen kebijakan yang dikeluarkan pimpinan rumah sakit.

Tulisan ini merekomendasikan agar manajemen rumah sakit agar selalu menjalin komunikasi dan memotivasi kepala ruangan untuk melakukan inovasi dalam menjalankan fungsi pengendalian mutu keperawatan. Pelibatan kepala ruangan secara aktif dalam pelaksanaan program penjaminan mutu dari mulai penetapan indikator, pengumpulan data, analisis data, publikasi hasil capaian sampai dengan tindakan perbaikan dan evaluasi. Penjaminan mutu terlaksana dengan baik apabila kepala ruangan agar terus menerus mengembangkan diri dengan meningkatkan pengetahuan dan wawasan mengenai mutu keperawatan. Hal yang tidak kalah pentingnya adalah pelibatan staf perawat dalam menetapkan dan melaksanakan perbaikan berkelanjutan untuk meningkatkan mutu pelayanan keperawatan.

\section{DAFTAR PUSTAKA}

Rehan, A. \& Kanji, Z., J. D., R. R. (2015). Perceptions of patients regarding quality nursing care (QNC) at a tertiary care hospital, Karachi, Pakistan. Journal of Clinical Research \& Bioethics, 06(06).

Bentley, T. A. (2017). Performance data and staff responsibility (doctoral dissertation). Walden University, Minneapolis, MN, USA.

Ezeukwu, D. N. (2011). Nurse leader competencies and their relationship to quality of nursing care: A case study. Ann Arbor: ProQuest LLC.

Farquhar, M. (2008). AHRQ quality indicators. In Hughes, R. G., Ed. Patient safety and quality: an evidence-based handbook for nurses. Washington: AHRQ Publication. 
Fergus, J.-A. M. (2012). Nurse manager leadership in unionized acute care hospitals in massachusetts, staff nurse empowerment, and retention. Ann Arbor: ProQuest LLC.

Giesbers, A. P., Schouteten, R. L., Poutsma, E., van der Heijden, B. I., \& van Achterberg, T. (2016). Nurses' perceptions of feedback to nursing teams on quality measurements: An embedded case study design. Int J Nurs Stud, 64: 120-129.

Hariyati, R. T. S. (2014). Perencanaan, pengembangan dan utilisasi tenaga keperawatan (1st ed.). Jakarta: Rajawali Pers.

Heslop, L., \& Lu, S. (2014). Nursing-sensitive indicators: A concept analysis. J Adv Nurs, 70(11): 2469-2482.

Huber, D. (2014). Leadership \& nursing care management (5th ed.). St. Louis Missouri: Elsevier Saunders.

Hughes, R. G. (2008). Patient safety and quality: an evidence-based handbook for nurses. In R. G. Hughes, Ed, Agency for healthcare research and quality, US Department of Health and Human Services. Washington: AHRQ Publication.

Joint Commission International. (2017). Joint Commission International Accreditation standards for hospitals (6th ed.). Oak Brook: Department of Publications Joint Commission Resources.

Jones, T. L. (2016). Outcome measurement in nursing: Imperatives, ideals, history, and challenges. Online Journal of Issues in Nursing, 21(2)

Kelloway, E. K., Barling, J., \& Helleur, J. (2000). Enhancing transformational leadership: The roles of training and feedback. Leadership \& Organization Development Journal, 21(3): 145-149.
Kementerian HAM RI. (2009). UndangUndang Republik Indonesia nomor 44 Tahun 2009 tentang Rumah Sakit. Jakarta, Indonesia.

Kementerian HAM RI. (2014). UndangUndang Republik Indonesia Nomor 38 Tahun 2014 tentang Keperawatan. Indonesia.

Kol, E., Arıkan, F., Ilaslan, E., Akinci, M. A. \& Koçak, M. C. (2018). A quality indicator for the evaluation of nursing care: determination of patient satisfaction and related factors at a university hospital in the Mediterranean Region in Turkey. Collegian, 25(1): 51-56.

Komisi Akreditasi Rumah Sakit. (2012). Panduan penyusunan dokumen akreditasi (1st ed.). Jakarta: KARS.

Komisi Akreditasi Rumah Sakit. (2017). Standar Nasional Akreditasi Rumah Sakit. Jakarta, Indonesia: KARS.

Lucas, B. \& Nacer, H. (2015). The habits of an improver: Thinking about learning for improvement in health care. London: The Health Foundation.

Manning, J. M. (2014). The influence of nurse manager leadership style factors on the perception of staff nurse structural empowerment, work engagement, and intent to stay. Ann Arbor: ProQuest LLC.

Marquis, B. L., \& Huston, C. J. (2015). Leadership roles and management functions in nursing: Theory and application (8th ed.). Canada: Lippincot Williams \& Wilkins.

Mendes, L., \& Fradique, M. J. J. G. (2014). Influence of leadership on quality nursing care. International Journal of Health Care Quality Assurance, 27(5): 439-450.

Montalvo, I. (2007). The national database of nursing quality Indicators ${ }^{\circledR}$ (NDNQI ${ }^{\circledR}$ ). The Online Journal of Issues in Nursing, 12(3). 
Mudallal, R. H., Saleh, M. Y. N., Al-Modallal, H. M., \& Abdel-Rahman, R. Y. (2017). Quality of nursing care: The influence of work conditions, nurse characteristics and burnout. International Journal of Africa Nursing Sciences, 7: 24-30.

Muhidin, M., Sahar, J., \& Wiarsih, W. (2010). Persepsi pasien terhadap pelayanan keperawatan: Studi fenomenologi. Jurnal Keperawatan Indonesia, 13(2): 74-80.

Needleman, J., \& Hassmiller, S. (2009). The role of nurses in improving hospital quality and efficiency: real-world results. Health Aff (Millwood)), 28(4): w625-633.

Neuhauser, D. M. (2011). Impact of staff engagement on nurse satisfaction/ retention and patient outcomes of patient satisfaction and NDNQI® indicators (Master's thesis). Western Carolina University, Cullowhee, USA.

NSW Goverment. (2013). Workplace policies and procedures. Retrieved from http:// www.industrialrelations.nsw.gov.au/biz res/oirwww/pdfs/workplace_pp.pdf

Pianella, T. A. (2014). Transformational leadership impacting staff nurse job satisfaction as it relates to quality of care. Ann Arbor: ProQuest LLC.

Raines, D. A. (2012). Quality improvement, evidence based practice, and nursing research.... Oh my!. Neonatal Netw, 31(4): 262-264.

Rizany, I., Hariyati, R. T. S., \& Handiyani, H. (2018). Factors that affect the development of nurses' competencies: A systematic review. Enfermeria Clinica, 28: 154-157.

Schwartz, L. C. (2017). Why are policies \& procedures important for succession planning? Small business. Retrieved from http://smallbusiness.chron. com/policies-procedures-importantsuccession-planning-946.html
Sigit, A., Keliat, B. A., \& Hariyati, R. T. S. (2011). Fungsi pengarahan kepala ruang dan ketua tim meningkatkan kepuasan kerja perawat pelaksana. Jurnal Keperawatan Indonesia, 14(2): 83-88.

Suhariyanto, Hariyati, R. T. S., \& Ungsianik, T. (2018). Improving the interpersonal competences of head nurses through Peplau's theoretical active learning approach. Enfermeria Clinica, 28: 149153.

Thabane, L. (2004). Sample size determination in clinical trials HRM-733 class notes. Hamilton: Department of Clinical Epidemiology \& Biostatistic. Retrieved from http://www.lehanathabane.com

Thabane, L., Ma, J., Chu, R., Cheng, J., Ismaila, A., Rios, L. P., Robson, R., ..., Goldsmith, C. H. (2010). A tutorial on pilot studies: the what, why and how. BMC Med Res Methodol, 10(1): 1.

The Agency for Healthcare Research and Quality. (2008). Toolkit for using the AHRQ quality indicators: How to improve hospital quality and safety. In Hughes, R. G., Ed, Patient safety and quality: An evidence-based handbook for nurses. Washington: AHRQ Publication.

Yasman, Y., Sahar, J., \& Nuraini, T. (2015). Model kepemimpinan kepala ruangan menurut pandangan perawat pelaksana berhubungan dengan retensi. Jurnal Keperawatan Indonesia, 18(1): 31-37.

Zoschak, E. W. (2010). 10 indicators of excellent nursing care. Trustee: The Journal for Hospital Governing Boards, 63(9), 28-30, 1. (sumber tidak dapat ditelusuri) 